\title{
SONS E MÚSICA NA OFICINA DA HISTÓRIA
}

O volume Modinhas Imperiais compilado por Mário de Andrade apresenta uma composição - O coração perdido - de autoria do engenheiro Frederico Luis Guilherme de Varnhagen (1782-1842). O autor teria escrito ainda outras modinhas, entre elas $A$ saudade, de valor musical questionável e, por isso, não incluídas na coleção pelo musicólogo ${ }^{1}$. O sobrenome do compositor é revelador: aponta que se tratava do pai do historiador Francisco Adolfo Varnhagen que, certamente, iniciou seus primeiros contatos com a música no ambiente familiar. Esta proximidade e interesse musical de certo modo permaneceram ao longo da carreira intelectual do historiador. Na sua infatigável procura por fontes para construir uma história do Brasil, o Visconde de Porto Seguro encontrou e comentou documentos híbridos entre a poesia e a música, com os sugestivos nomes de Trovas e cantares de um códice do XIV século: ou mais provavelmente, o livro de cantigas do conde de Barcelos e Cancioneirinho de trovas antigas colligidas de um grande cancioneiro da biblioteca do Vaticano. No seu Florilégio da poesia brasileira, obra de 1850 destinada a destacar os principais poetas brasileiros, o historiador apresentou a biografia do poeta, mas também compositor e cantor, Domingos Caldas Barbosa, o mestiço “cantor de viola" ${ }^{2}$. Claro que na produção historiográfica conservadora do historiador, voltada essencialmente à

\footnotetext{
${ }^{1}$ ANDRADE, Mário de. Modinhas imperiais. Modinhas de salão brasileiras, do tempo do Império, para canto e piano. São Paulo: Casa Chiarato Ed., 1930, p.13.

${ }^{2}$ VARNHAGEN, F. A. Florilégio da poesia brasileira, 3 vols. Rio de Janeiro: Academia Brasileira de Letras, 1946, p. 42. O texto foi republicado no ano seguinte, com algumas modificações, na seção "Biografias” da Revista do Instituto Histórico e Geográfico Brasileiro (vol. 14, 1851), com o título "Domingos Caldas Barbosa”.
} 
história política e administrativa, a música aparece de maneira muito marginal. De qualquer modo, é curioso conhecer essa proximidade pessoal e intelectual do tradicional historiador oitocentista com a música.

É interessante notar que Capistrano de Abreu - que manteve permanente relação de profundo respeito e conflito com a obra de Varnhagen - ao esboçar um tipo de história social e cultural do povo brasileiro no início do século XX, também fez referências à música na obra Capítulos de História Colonial. Nela a música surge de maneira tangencial, presente nas festas populares, nas irmandades religiosas da região mineradora e nos cantos de trabalho no Rio de Janeiro $^{3}$. Já a produção historiográfica da geração imediatamente posterior ao historiador cearense teve relação bastante refratária com os sons e a música. Na obra de Caio Prado Jr., são totalmente inexistentes. Sérgio Buarque de Holanda, embora convivesse no cotidiano com músicos e poetas, em Raízes do Brasil fez apenas pequena referência à música na festa de Bom Jesus de Pirapora, em São Paulo, quando Jesus Cristo "desce do altar para sambar com o povo" " . O contraponto foi a obra em três andamentos de Gilberto Freyre sobre a formação e decadência da sociedade patriarcal no Brasil, em que desponta uma abundância de sons, ritmos, músicas e canções. No primeiro volume, Casa Grande e Senzala, os ritmos africanos se misturam às canções infantis e de ninar, às músicas das festas profanas e religiosas, e aos lundus e modinhas. No volume Sobrados e Mocambos surgem as modinhas tocadas ao piano pelas moças, as músicas dos salões e também as das ruas, feitas pelo violão e batuques. Em Ordem e Progresso a música aparece de forma destacada com comentários sobre modinhas, polcas e dobrados, entre outros gêneros, e surge até documentada em forma de partituras. Mas Gilberto Freyre é exceção no quadro historiográfico brasileiro. Infelizmente o esboço, ainda que rarefeito, das relações entre música e trabalho historiográfico proposto por ele teve continuidade muito dispersa e limitada entre os historiadores de ofício. Nas gerações seguintes, a generalizada “surdez dos historiadores" - apontada pela musicóloga

\footnotetext{
${ }^{3}$ ABREU, Capistrano. Capítulos de História Colonial. Belo Horizonte/São Paulo: Ed. Itatiaia/Edusp, 1988, capítulo XI, “Três séculos depois”.

${ }^{4}$ HOLANDA, Sérgio Buarque. Raízes do Brasil. 8 a ed. Rio de Janeiro: Livraria José Olympio, 1975, p. 110.
} 
Myriam Chimènes no artigo traduzido neste volume da Revista de História permaneceu e muitas vezes se aprofundou.

Ecoando essa dinâmica da historiografia, a Revista de História, assim como outras publicações especializadas, seguiu o mesmo ritmo e as publicações relativas à música são episódicas. O número de artigos publicados relacionados ao tema ao longo dos seus cinqüenta anos não soma os doze sons da escala cromática: foram somente onze textos, sendo oito deles de autoria de apenas três autores ${ }^{5}$. Claro que esse relativo silêncio revela também a rarefação das investigações em torno da música e as dificuldades em desenvolver pesquisas na oficina da História até pelo menos a década de 1990. Essa situação repleta de obstáculos é perfeitamente visível na trajetória docente e de pesquisador do professor Arnaldo Contier. Em depoimento exclusivo para a Revista de História ele apresenta e comenta as dificuldades enfrentadas pelo historiador de ofício em tratar com o objeto sonoro. Durante anos ele foi uma espécie de solista na formação de pesquisadores e na evolução deste novo campo de pesquisa. É preciso salientar, no entanto, que as dificuldades não eram exclusivas dos historiadores. Artistas contemporâneos e musicólogos passaram por conflitos e angústias semelhantes durante o mesmo período. Embora tenham ocorrido profundas transformações nos meios de registro e difusão da música, pesquisar, compor e difundir trabalhos com propostas e linguagens renovadoras tornouse cada vez mais difícil, como nos revela o texto também publicado neste volume, em chave dissonante mahagonnense e tom claramente brechtiano de manifesto, do pesquisador e compositor Willy Correa de Oliveira.

A relativa surdez historiográfica não era, porém, uma situação exclusiva da produção brasileira. O referido artigo da musicóloga francesa mostra situação

\footnotetext{
${ }^{5}$ Três do historiador e musicólogo Régis Duprat: “Música nas Mogis Mirim e Guassú”, n. 58, abril-junho, 1964; “A música na Bahia colonial”, nº 61, janeiro-março, 1965; "Música na matriz de São Paulo colonial”, n 75 , julho-setembro, 1968. Três do musicólogo alemão Francisco Curt Lang: “Um fabuloso descobrimento”, n 107, julho-setembro, 1976; “O progresso da musicologia na América Latina”, n 109, janeiro-março, 1977; "Os primeiros subministros musicais do Brasil para o Rio da Prata”, n 112, outubro-dezembro, 1977. Dois do historiador Arnaldo Contier: "Música e História”, n 119, julho-dezembro, 198588; "Villa Lobos, o selvagem da modernidade", $\mathrm{n}^{\circ} 135,2^{\circ}$ semestre 1996. Os três restantes são “O Samba em Itu”, de Otávio Ianni, n 25, janeiro-março, 1956; “As óperas de Puccini”, Antonio Almeida Prado, n 58, abril-junho, 1964; "Rádio e música popular nos anos 30”, de José Geraldo Vinci de Moraes, nº 140, $1^{\circ}$ semestre, 1999.
} 
semelhante no contexto europeu, sobretudo o francês, das décadas de 1980/ 90. Antes deste período, raros foram os historiadores de ofício, como HenryIrenée Marrou, que se arriscaram nesta área de pesquisa. Nos anos '40 ele publicou alentada obra de tonalidades folcloristas ${ }^{6}$ - recheada de músicas, letras de canções, análises melódicas e harmônicas - e um pequeno tratado sobre a música em Santo Agostinho ${ }^{7}$. Em ambos os livros ele utilizou o pseudônimo de Henri Davenson, recurso também usado por Eric Hobsbawm para publicar sua história social do jazz, em 1959, com o nome de Francis Newton ${ }^{8}$. Esse fato não pode passar despercebido, pois na verdade revela que dois importantes historiadores do século XX procuraram resguardar, por algum motivo, seus nomes em obras que tratavam da música, mais especificamente a popular. Em tom diferente da sociologia e da antropologia, poucos foram os historiadores que realizaram pesquisas tendo a música como objeto ou fonte documental antes dos anos '90. Foi somente nesta década que começaram a surgir alguns trabalhos, como destaca o artigo de Myriam Chimènes. Provavelmente, esse contexto favorável permitiu ao historiador francês Alain Corbin, por exemplo, realizar inusitada obra sobre como os sons dos sinos que presidiam o ritmo da vida rural se transformaram no século XIX, implicando mudança de sensibilidade e de escuta ${ }^{9}$. Nela, Corbin usou o conceito de paisagem sonora como uma forma de ampliar os horizontes de discussão de sua história das paisagens e das sensibilidades ${ }^{10}$. Nesta mesma linha seguiu Jean-Pierre Gutton que, além dos sinos, incluiu nessa nova "paisagem sonora” - já se referindo claramente ao conceito de Murray Schafer $^{11}$ - os sons das cidades, das oficinas, entre outros ${ }^{12}$.

\footnotetext{
${ }^{6}$ DAVENSON, Henri. Introduction à la connaissance de la chanson populaire française. Le livre des chansons. Neuchâtel : Ed. de la Baconnière, 1982.

${ }^{7}$ Idem, Traité de la musique, selon l'espirit de saint Augustin. Paris : Seuil, 1942.

${ }^{8}$ NEWTON, Francis. História social do jazz. São Paulo: Paz e Terra, 1990.

${ }^{9}$ CORBIN, Alain. Les cloches de la terre. Paysage sonore et culture sensible dans les campagnes au XIX siècle. Paris : Flammarion, 1994.

${ }^{10}$ Idem, “Du Limousin à les cultures sensibles”. Jean-Pierre Rioux e Jean-François Sirinelli (dir.), Histoire culturelle de la France. Paris : Seuil, 1997.

${ }^{11}$ SCHAFER, R. Murray. A afinação do mundo. São Paulo: Ed. Unesp, 2001.

${ }^{12}$ GUTTON, Jean-Pierre. Bruit et sons dans notre histoire. Paris: PUF, 2000.
} 
Foi nesta década que ocorreram também as principais mudanças na produção historiográfica brasileira relativa à música, condição salientada no artigo de Marcos Napolitano. Seu texto aborda especificamente a evolução dos estudos sobre a música popular brasileira que ocorreu neste período, tendo como ponto de partida sua própria trajetória e a de sua geração. Na realidade, a historiografia entrou tardiamente nesse tradicional debate sobre a música popular e suas relações centrais na construção da “cultura nacional”. As discussões em torno do tema ampliaram-se, deixando para trás tanto as concepções folcloristas como a percepção adorniana da indústria cultural e a noção de "cultura de massas” presentes ainda em certa sociologia dos anos ‘70/“80. Porém, sem cabedal teórico acumulado e limitada em sua tradicional surdez, a História colocou em marcha mais uma vez sua vocação interdisciplinar como forma de aprofundar seus contatos com o universo sonoro e musical. Neste passo, Elizabeth Travassos mostra em seu artigo como a história se aproximou da etnomusicologia em mudança, e vive-versa, no mesmo compasso da (re) aproximação de ambas com a antropologia. Ela destaca justamente que "os tempos são propícios à 'mistura de gêneros'”, e que, portanto, os diálogos entre os diversos campos do conhecimento devem continuar sendo observados e aprofundados.

O debate em torno da música popular se aprofundou na América Latina ao longo das duas últimas décadas numa clave bem mais dinâmica e criativa que a européia, provavelmente revelando a riqueza e o hibridismo de nossos gêneros musicais. O texto do musicólogo chileno Juan Pablo Gonzáles e também sua militância como presidente da seção latino-americana da International Association for the Study of Popular Music em favor de uma "musicologia da música popular” revelam essa cadência. A valorização estética e cultural da música popular é eixo importante de sua concepção, assim como do musicólogo argentino Diego Fischerman, cuja obra é resenhada no final do dossiê. Além disso, seu artigo escrito em conjunto com o historiador chileno Claudio Rolle oferece uma discussão sobre as possibilidades de diálogo teórico e metodológico entre essa “outra musicologia” e a História, apontando para a necessidade de se pensar uma história social da música popular. O artigo escrito em dueto revela grande preocupação com a prática historiográfica e, consequentemente, com as fontes escritas, fonográficas, performáticas, memorialísticas, mas também com o universo da criação e da recepção musical. Essa discussão sobre fontes, arquivos e criação musical, com variação de tom mais próximo da música erudita, também é apresentada pela musicóloga Flávia Toni. Para ela, a parceria entre 
Biblioteconomia, Arquivologia, Música e História é central para acompanhar a dinâmica crescente da produção acadêmica, como também para facilitar a pesquisa criadora dos compositores. Num quadro precário e disperso de centros de referência, discotecas, bibliotecas e arquivos especiais - os existentes ainda sob controle de instituições privadas ou em mãos individuais -, o tema ganha importância adicional e contornos de urgência.

As discussões realizadas ao longo destas décadas - algumas delas reveladas neste dossiê - apresentaram diversas características e tonalidades, entre elas a dificuldade em operar com os tradicionais conceitos de música erudita e popular e as abordagens que eles determinaram. Tornou-se cada vez mais difícil pensar a música e as investigações sobre ela nessas fronteiras tradicionais, sobretudo porque a prática musical, em boa parte de nosso continente, permitiu historicamente as mais inusitadas formas de misturas, fusões, hibridizações, circulação e difusão entre variadas culturas musicais. O texto de José Miguel Wisnik nos mostra como esses limites na cultura musical brasileira, entre os anos '20 e ’50, foram completamente devassados, produto de uma prática cultural singular, repleta de conflitos e diálogos. Tendo esse tom como eixo, o texto historiciza a criação musical do período, relacionando-a no quadro cultural mais abrangente com a literatura, o cinema e até o futebol. Assim, a tradição de aproximar literatura e ciências sociais transborda também para a música e a história. Na realidade, suas obras procuram a todo o momento esse difícil equilíbrio entre as análises estéticas e musicais e o universo cultural e social que fazem parte delas. E é essa dinâmica que lhe permite ensaiar interpretações de longa e média duração da cultura brasileira, como faz na mesma clave em Machado Maxixe: o caso Pestana $^{13}$. Essas criativas contribuições, originadas da área de Literatura, associadas posteriormente à Semiótica e à Lingüística, como nos revela a resenha sobre o livro de Luiz Tatit, tornaram-se referência para aqueles que pretendem justamente ultrapassar as tradicionais fronteiras analíticas e aprofundar as discussões da presença crucial da música na nossa cultura.

A apresentação deste dossiê da Revista de História pretende justamente colaborar para a ampliação e o aprofundamento do debate, mas, sobretudo, tirar a História e os historiadores do relativo silêncio a que estiveram submetidos

\footnotetext{
${ }^{13}$ WISNIK, José Miguel. "Machado, Maxixe: o caso Pestana”. Teresa 4/5. Revista de Literatura Brasileira, São Paulo: USP/Ed. 34, 2004, pp. 13-79.
} 
desde os contatos residuais de Varnhagen com a música. Quem sabe indique que provavelmente a "surdez dos historiadores" está em processo de cura e que esse volume da Revista de História contribui para o seu tratamento. Além disso, ele quer discutir qual o papel que a História pode desempenhar de modo específico, com seus instrumentos analíticos e interpretativos, para ampliar a discussão e criar seu próprio campo de investigação. Mas isso significa estabelecer permanente diálogo com outras disciplinas - como revelam os textos do dossiê - e exercer claramente nossa vocação interdisciplinar intrínseca. E se, ao final, o leitor julgar que nenhum desses objetivos foi alcançado, esperase ao menos que compreenda a música, "mais que um objeto de estudo, (...) um meio de perceber o mundo", e que nela às vezes repousam as novas formas sociais e culturais que virão ${ }^{14}$.

José Geraldo Vinci de Moraes

${ }^{14}$ ATTALI, Jacques. Bruits. Essai sur l'économie politique de la musique. Paris: PUF, 1977, p. 9. 